\title{
EL RITMO EN LA LITERATURA Y EL CINE
}

\author{
Rafael Núñez Ramos
}

Universidad de Oviedo

\section{LITERATURA Y CINE COMO FORMAS DE ARTE TEMPORAL}

La relación entre el cine y la literatura puede establecerse en distintos niveles. Como manifestaciones artísticas entran en el dominio de la estética y constituyen una forma específica de conocimiento y comunicación cuyas particularidades se pueden comprender mejor, si nos situamos en un nivel más concreto y analizamos sus diferencias y semejanzas en cuanto artes de la duración, esto es de la sucesión y del tiempo. El cine, entonces, mantiene relaciones con las tres grandes clases de literatura: como la literatura dramática (el teatro) muestra personajes actuando directamente ante el espectador; como en la narrativa, sin embargo, esta actuación aparece organizada por una instancia que mira (homóloga a la que se denomina «voz» en la novela, por ejemplo); como la lírica, en fin, que se presenta en forma de verso, memoria de un origen en que el poema se acompañaba con la lira, el mensaje cinematográfico contiene una banda sonora frecuentemente musical. 
No pretendemos conceder a la música un papel decisivo en nuestro estudio, sino analizar, a partir de su relación tanto con la poesía como con el cine, cómo su presencia es síntoma de la necesidad de organizar el discurso fílmico de manera que su percepción, guiada por el movimiento rítmico (característico de la lírica) que se superpone y modeliza las estructuras narrativas y dramáticas, constituya una forma de conocimiento sensible, complejo y afectivo, no conceptual, como corresponde a su pretensión estética. Y no creemos que en el cine sea la música el principal soporte de esta organización, sino el ritmo, «porque, como señala Jean Mitry (1966: 351), si la música parece hallarse en el origen de toda expresión, es porque se confunde música con ritmo, principalmente con el ritmo de los gestos y el comportamiento humano.

\section{LA RESPUESTA ESTÉTICA}

Cine y literatura, decíamos, se nos presentan como formas de arte, por lo tanto como objetos que promueven en quien se acerca a ellos la respuesta estética. La experiencia estética consiste en una relación inmediata entre el sujeto y el objeto, un contacto directo, personal, sensible (no conceptual), subjetivo, no mediatizado por ningún apriorismo, ni siquiera el apriorismo del lenguaje, a través de cuyo sistema de categorías, estructuras, clasificaciones y etiquetas se filtra y encauza la mayor parte de nuestra experiencia. En breves palabras, en el conocimiento estético, el acto de percepción sólo está gobernado por la naturaleza concreta e idiosincrásica del objeto y por la iniciativa del sujeto que responde implicándose afectivamente, y no contemplando e interpretando intelectualmente el objeto. Como ya dijera Kant, lo estético es de naturaleza no conceptual, por ello inexpresable en palabras, salvo las palabras desconceptualizadas de la obra de arte literaria.

En las artes temporales este tipo de experiencia puede identificarse con la aprehensión rítmica del objeto, la cual es estimulada por la organización del objeto según criterios métricos. La métrica (y el ritmo que promueve) alcanza su manifestación más notoria en el ámbito de la poesía, en la presentación marcadamente artificial de las estructuras lingüísticas que la forman y en la potenciación de su condición sensorial, sonora, mientras que en el cine, por la heterogeneidad de los 
materiales que utiliza, la extensión con que se desarrolla y la linealidad irrecuperable de su despliegue, parecen ocultarse y eludir el análisis, aunque no su acción y eficacia, como trataremos de mostrar. Pero aprovechando esta ostentación que la poesía hace de su organización métrica abocada al ritmo, vamos a comenzar estudiando simultáneamente el concepto de ritmo en general y su funcionamiento en los textos poéticos, para, en un segundo momento, tratar de estudiar los estímulos métricos del filme y su función rítmica, en parangón con el modelo poético definido previamente.

El ritmo, «esa violencia que renueva el orden de todos los átomos de la frase» (Nietzsche), es la expresión misma del efecto estético del poema, pues en el ritmo se produce no ya la fusión de todos los planos y niveles del objeto poético, sino la incorporación de éste en su globalidad en el organismo mismo del observador y la supresión de la separación entre sujeto y objeto; todavía más, el ritmo es la forma de existencia estética del poema, pues sólo en su ejecución gobernada por las exigencias del ritmo alcanza consistencia y concreción, se vuelve sensible, el material abstracto del lenguaje que lo sustenta; ninguna manifestación del ritmo más genuina que los movimientos corporales con que acompañamos una pieza musical, movimientos que no son sustancialmente distintos del movimiento y la respiración interior que tienen lugar de manera casi imperceptible e inconsciente, pero en todo caso inequívoca, cuando leemos para nosotros un poema.

El lenguaje, basado en la abstracción, en la relación no necesaria, convencional y arbitraria entre significante y significado, constituye una de las proyecciones que separan al hombre de su entorno y de sí mismo. Ligado a la comprensión y al pensamiento, el lenguaje, en su funcionamiento habitual, deja a un lado lo sensible para aplicarse a lo conceptual, al plano del contenido.

Pero la materia propia del lenguaje, el sonido, es de naturaleza sensorial. El plano de la expresión modula la dimensión física y sensorial del lenguaje en cada lengua, vinculándola con el plano del contenido en una relación de solidaridad, según la cual ambas son inseparables: el contenido se manifiesta en una expresión y la expresión lo es de un contenido.

El decurso lingüístico ordinario impone a la expresión las leyes del contenido, la cadena fónica se organiza de acuerdo con las normas sintáctico-semánticas; apela a la mente del sujeto, que deberá obtener la información interpretando el significado de las unidades y de las relaciones gramaticales que contraen, es decir, sustituyendo la forma física de las unidades, que pierde todo valor, por su sentido. 
El decurso poético, en cambio, sin prescindir de la organización del contenido, la somete al dictado de la expresión. El verso, decían los formalistas rusos, es un discurso organizado en su trama fónica total. El poema, como concatenación de sonidos y unidades melódicas, forma un todo estructurado: la trama fónica constituye el argumento poético en el que la lógica fónica y musical impera sobre la lógica de las acciones representadas o de los pensamientos formulados.

\section{EL RITMO COMO REGULARIDAD Y COMO MOVIMIENTO}

Sin duda, como ha mostrado Lenneberg, el ritmo es inherente a la producción del lenguaje en todo caso, «existe un ritmo de habla que sirve como principio organizador y quizá como aparato de cronometraje para la articulación». Pero en el habla, el ritmo se pliega a las necesidades del contenido. La naturalidad con que se produce no da lugar a excesivas variaciones individuales y su condición de esquema motor universal lo hace relativamente constante (Lenneberg, 1945: 134-147). Lo que ocurre en realidad es que el ritmo, de una manera más general, constituye un principio básico en el desarrollo de la actividad vital: «nuestra vida misma, afirma S. Langer (1967: 107), se mide por el ritmo, por nuestra respiración, por los latidos de nuestro corazón». Con todo, en el transcurrir de la vida, los ritmos se automatizan, se sumergen en niveles más o menos inconscientes de la mente y se empobrecen a causa de la preeminencia del pensamiento consciente y pragmático, difuminándose así la sensación de vida, el sentido del momento. No es de extrañar, pues, que en el habla el ritmo se reduzca a un fondo necesario para la articulación, que no se vuelve figura ni ocupa por tanto el foco de la conciencia, pues el sentido lo sustituye de inmediato, como tampoco es de extrañar que, a la inversa, en la poesía adquiera valor por sí mismo, vuelva a la vida, ya que el lado físico del lenguaje en el que se apoya necesita para su realización el aliento de cada lector. El poema «tiene que ser respirado» (Domin, 1986: 190), y no hay respiración posible si el ritmo no la conduce.

El ritmo, a su vez, se apoya en la medida, en la regularidad, en la previsión, es decir, en la métrica, pero va más allá, pues incorpora en el molde métrico abstracto toda la riqueza y variedad de la realización concreta, todos los formantes que comporta la pronunciación efectiva y los ecos afectivos y semánticos que pueden movilizar las unidades lingüísticas puestas a pleno rendimiento. 
Por eso, una definición de ritmo como la de los formalistas rusos, «la alternancia regular en el tiempo de fenómenos comparables», por estar ligada en exceso al componente métrico, no es del todo adecuada e incluso contradice su condición más característica, pues atribuye al ritmo un matiz de fijeza y objetividad (por el carácter regular y comparable de los fenómenos) que, aun sirviéndole de base, queda trascendida en el dinamismo vital con que se despliega y ejecuta.

Más interesante resulta entonces una fórmula como la de Benveniste para quien ritmo significa, atendiendo rigurosamente a su valor etimológico, «forma en movimiento». Si la definición de los formalistas aproxima el ritmo a su base métrica, de carácter mecánico, la noción de forma en Benveniste, por el contrario, sin prescindir de la idea de «configuración», de «orden» incluso, que le es esencial, se aleja definitivamente de la fijeza y la objetivación, pues precisamente rithmós designa en griego «la forma en el momento mismo en que es asumida por lo que es movedizo, inestable, fluido, la forma de lo que no tiene consistencia orgánica... Es la forma improvisada, momentánea, modificable» (Benveniste, 1974: 333). La investigación de Benveniste, puramente filológica, resulta reveladora de aspectos inequívocos de lo poético, subrayando además su condición dinámica y, por tanto, vital.

En cuanto movimiento, el ritmo se encuentra ligado íntimamente a los organismos vivos, es un principio de vida; en el caso de la poesía el ritmo se presenta, entonces, como una característica de su ejecución que el texto promueve precisamente por estar organizado según criterios métricos, esto es, por disponer de forma regular ciertos estímulos.

Efectivamente, si aceptamos como punto de partida la definición de ritmo de los formalistas, asumiendo el papel que desempeña la métrica, descubrimos que el ritmo ha de ser cuestión de totalidad, porque sólo teniendo presente el conjunto podremos tener conocimiento de qué fenómenos comparables se producen y a qué intervalos. El ritmo parece exigir una percepción sinóptica y global. Pero su carácter sensorial, su manifestación a través de la linealidad sonora del lenguaje hacen imposible este tipo de aprehensión. El ritmo es un fenómeno, una respuesta corporal que la métrica y la condición de totalidad no sólo no contradicen, sino que estimulan, pues es la regularidad el factor que promueve la forma del movimiento al crear un sistema de expectativas por el que se rigen los impulsos fisiológicos que intervienen en la fonación. El ritmo es el movimiento corporal hacia un estímulo que se presiente en razón de su equivalencia con un estímulo sobrevenido en un momento anterior también equivalente en su ubicación temporal. Es la 
anticipación del estímulo la que orienta las decisiones que dan forma a toda la sucesión de fenómenos sonoros, la que determina la entonación, la curva melódica, los énfasis intermedios; es, pues, la regularidad métrica la que dirige los movimientos del cuerpo y la que invita a enlazar unos estímulos con otros en una sucesión continua de anticipaciones que son a la vez evocaciones, puesto que el estímulo pre-sentido lo es por la propulsión de un estímulo precedente. El ritmo se halla precisamente en ese impulso de preparación de un nuevo acontecimiento cuando el anterior está finalizando, sin que el acontecimiento presentido deba consumarse exactamente, pues basta con que mantenga el sistema de relaciones que vincula los extremos y da forma a los intervalos. Pues el ritmo se basa en la concatenación ininterrumpida de los estímulos, en la presencia en un acontecimiento de los acontecimientos que lo impulsaron y de los acontecimientos en que se habrá de transformar, en la tensión vivida en cada momento (presente) entre la energía que parece consumirse y la que empieza a brotar.

Anticipación y evocación, memoria y expectativa son los dos momentos subjetivos que regulan y conforman el ritmo, el dibujo que hace en el cuerpo del lector la pronunciación del poema; no han de entenderse, pues, como dimensiones de una subjetividad mental y semántica, sino corporal, sensible y emotiva; por eso, más que de memoria y expectativa tal vez haya que hablar de un impulso hacia adelante que lleva la huella del estímulo que lo proyectó. Se observará, entonces, cómo en el ritmo se realiza aquella condición de actualidad permanente característica de la experiencia estética, pues cada momento de la lectura es un impulso que conserva el principio y anticipa el final. «El ritmo poético es la actualización de ese pasado que es un futuro que es un presente: nosotros mismos. La frase poética es tiempo vivo, concreto; es ritmo, tiempo original, perpetuamente recreándose» (Paz, 1976: 66). Y este fluir constante de la temporalidad se alcanza precisamente por la inscripción del sentido en los movimientos corporales en los que el ritmo sobreviene y es experimentado por el receptor.

\section{EL RITMO CINEMATOGRÁFICO}

Uno de los sentidos de la palabra «poesía» es el que resulta de identificarla con «verso» y, por tanto, de oponerla a «prosa». La diferencia fundamental entre ambas se encuentra en el carácter de la organiza- 
ción métrica, sistemático y prioritario en la poesía, coyuntural y accesorio en la prosa. Antes de analizar los mecanismos métrico-rítmicos del cine, conviene preguntarse por una aplicación al mismo de este par de conceptos (poesía o verso y prosa) u otros homólogos.

La sutileza del ritmo cinematográfico, la irreversibilidad de su fluir lineal y la heterogeneidad de los elementos recurrentes han llevado a diversos teóricos a considerarlo como prosa: Adorno y Eisler (1981: 122-123), por ejemplo, hablan del carácter de prosa del cine, en completa contradicción con las repeticiones y las relaciones musicales de simetría.

Y efectivamente, es cierto que la organización cuantitativa del filme no sólo no se impone con la contundencia con que lo hace la del poema sobre la página, sino que resulta imperceptible a la mirada atenta, pero ingenua del espectador.

En mi opinión la situación es más compleja tanto en el cine como en la misma prosa artística, y ello porque las unidades mensurables que intervienen en estos casos no son las unidades fónicas elementales (sílaba, pausa, acento) que intervienen en el verso, sino unidades compuestas y no siempre homogéneas.

Por supuesto, puede haber un cine prosa, un cine organizado exclusivamente en función de la anécdota que quiere contar, narración elemental y directa, mera exposición de acontecimientos sucesivos no sometida a medida ni proporción, o sometida sólo accidentalmente. Pero en este tipo de cine la intención (orientación) estética aparece debilitada, la posibilidad de una respuesta afectiva global y conformada, que implique totalmente al espectador, sería remota, pues el ritmo es precisamente el principal factor en el que queda absorbido el ánimo entero del espectador y configura el sentido en una experiencia sensorial y connotativa (significación icónica y no convencional), gracias a su trabajo de renovar el orden de todos los átomos del plano y de llevar las modulaciones del movimiento de la imagen y su sentido al organismo del espectador en ese acompañamiento corporal tan característico.

Por eso nos interesa principalmente el cine poesía, es decir, el cine que superpone a la organización lógico-narrativa, basada en la coherencia significativa de los acontecimientos sucesivos, una organización formal, es decir, que utiliza los elementos en que los contenidos se manifiestan pero vinculándolos por sus propiedades materiales y formales específicas y no por lo que significan. Esto es, así como el ritmo 
del poema se apoya en la sucesión proporcionada de sílabas, acentos, pausas..., que son elementos constituyentes de las unidades de significación, pero se combinan, independientemente de su significación, según criterios cuantitativos de índole formal y material, el ritmo del cine se apoyará en los valores sensoriales, plásticos y formales de la imagen y la banda sonora, organizados según su naturaleza sensorial, plástica o formal, y no por su sentido inmediato. Es este desfase entre la organización del significante, que persigue la proporción y el ritmo, y la organización narrativa, basada en la coherencia secuencial de las acciones significativas, el que abre paso a toda una ola de rebotes y de ecos que transforman el sentido directo, denotativo y conceptual, en un sentido denso y difuso, connotativo y emocional, al tiempo que lo infunden corporalmente en el ánimo del espectador, en movimientos anímico-corporales en los que ese sentido se experimenta con precisión.

Lo que ocurre es que en la contemplación del filme respondemos a los estímulos métricos sin una conciencia plena de su existencia, como ocurre, por otra parte, con el poema, cuando la lectura nos absorbe y olvidamos el carácter artificial de su presentación gráfica.

Así pues, en su homología con la literatura, postulamos una doble condición del filme, narrativa, imitación de acciones, y poética, sometida a la medida y la proporción. En cuanto narración, el flujo de imágenes cinematográficas presenta una sucesión de acciones desde una mirada que las funda, organiza y expone; como poesía, la sucesión de imágenes ya no muestra acciones sino que ofrece estímulos sensoriales que se invocan mutuamente, independientemente del acontecimiento que contribuyen a representar. Analizaremos a continuación los tres niveles en que, según mi opinión, se pueden configurar estímulos rítmicos: la banda sonora, el montaje y la narración.

\subsection{La banda sonora}

Dentro de la banda sonora identificamos tres componentes que pueden formar conjuntamente el movimiento rítmico o bien alternativamente o bien en exclusiva. 


\subsubsection{La música}

Como ya señalamos, el uso abundante de la música en el cine constituye el indicio más evidente de que persigue los efectos estéticos del ritmo, aunque frecuentemente no trate sino de simularlos. Esto último es lo que ocurre cuando la música acompaña a la acción o anuncia cierto tipo de acontecimientos, puesto que sigue fielmente el movimiento narrativo, el curso de las acciones, su funcionalidad es enfática y redundante, como cuando al final de Casablanca subraya melodramáticamente la despedida de Rick y Elsa, ya de por sí melodramática. No remueve los átomos de la imagen, sino que los dobla o comenta innecesariamente. Para no caer en la prosa vagamente poetizante, la música debe marcar su propio camino que, por no tener significado propio, puede actuar, transformando, enriqueciendo (pues es claro que el sentido inmediato no se pierde) el de las imágenes: un ejemplo es el de la película de Greenaway El contrato del dibujante, donde se suceden las confluencias y bifurcaciones entre los dos planos.

El papel rítmico de la música en el filme se reconoce en la índole de los demás elementos con los que entra en correlación y en el carácter sintagmático, lineal, y no paradigmático, de la misma; relación sintagmática, pues el ritmo es sucesión de estímulos que se evocan mutuamente, y no acumulación, y, consiguientemente, relación con elementos de su misma índole sensorial (música antecedente o consiguiente, silencio o voz humana), o de índole homóloga (efectos visuales, movimientos de cámara, juegos de luces: recuérdese la música visual).

Frecuentemente la música interviene para cubrir espacios vacíos, para mantener la impresión de movimiento continuo que el ritmo necesita en situaciones en que el tiempo se detiene, como ocurre en las pausas descriptivas: puede observarse, por ejemplo, la diferencia de tratamiento que tienen los planos descriptivos, en que toda expectativa de acción ha quedado suspendida, que parecen pedir acompañamiento musical, frente a aquellos en que se detiene el movimiento de un personaje, pero se conserva la expectativa de acción, a los que conviene más el silencio. 


\subsubsection{La voz humana}

Nos referimos con estos términos no sólo a los diálogos de los actores, sino también a cualquier voz en off que pueda intervenir; de hecho, lo que se trata de subrayar es el valor rítmico que puede tener el sonido continuado de las voces y no la interacción comunicativa de los personajes; aunque, claro está, este valor imprime un carácter específico a la interpretación cinematográfica que la aleja notablemente de la teatral.

Dicen Aumont y Marie (1990: 216) que «el número de informaciones vehiculadas por el tono de las palabras, por su ritmo, por el timbre de la voz, e incluso las connotaciones derivadas de la mayor o menor musicalidad del habla, se hacen evidentes y nos sorprende por la importancia que adquieren». Y en efecto, la banda sonora aprovecha todas las cualidades que la voz humana manifiesta; sin embargo, la información que puedan transmitir no es tan relevante de manera inmediata y localizada en un segmento, como en una segunda fase y de manera global, cuando el ritmo general condiciona toda la percepción y transforma el sentido natural de las acciones narradas. La expresión de las actitudes y los caracteres de los personajes del filme no procede tanto de la voz y sus modulaciones, a diferencia de lo que ocurre en el teatro. En cambio, es característico de la interpretación cinematográfica cierta delgadez y transparencia en la dicción y una indudable sobriedad en la gesticulación (recuérdese la parodia que hace Fernán Gómez en El viaje a ninguna parte del actor teatral que de repente se ve obligado a hacer un breve papel para el cine) que, en mi opinión, se debe al sometimiento de cada uno de los intérpretes a una dicción no uniforme, pero sí homogénea y armónica, que lleva el ritmo del filme.

Este carácter rítmico y totalizador de la voz humana queda subrayado en el caso de las películas que se contemplan en versión original con subtítulos, pues en ese caso las palabras pronunciadas se ven libres del peso de la significación y actúan como un fondo estrictamente musical y rítmico, en el sentido fuerte, pues van desfasadas del sentido y, por tanto, lo someten.

«La palabra debe evitar ser una mera paráfrasis de la imagen», señala Marcel Martin (1962: 184), y en otro momento: «El mayor peligro que acecha a los directores, proveniente del diálogo, es el que haga prevalecer la explicación sobre la expresión». Ambas afirmaciones subrayan, a mi modo de ver, dos características notables de la palabra en el cine: 
1. Su función estructuradora, globalizante, es más un problema del director, como subraya Martin (1962: 185), que debe cuidar del conjunto, que de cada uno de los actores.

2. Su consistencia sensorial, más allá de la significación; es una palabra que actúa en cuanto estructura sonora más que en cuanto signo de otra cosa, exactamente igual que en la poesía.

Sin duda, esta generalización tiene sus excepciones que, como quedó señalado anteriormente, tienen que ver con los distintos géneros: ciertas formas de comedia, las que se fundan en la expresividad gestual, subordinan la palabra al movimiento de los actores, y entonces es éste el que soporta el ritmo y no la declamación sobria y cadenciosa. Pero no todas las comedias: piénsese, por ejemplo, en To be or not to be, que a pesar de referirse al mundo del teatro, basa sus efectos en la complejidad de las situaciones y no en la exageración de los gestos, y la palabra, declamada con un cuidado exquisito, con una detención que resulta caricaturesca precisamente si se considera desde la óptica teatral (piénsese por ejemplo en el momento en que el actor principal recita el famoso monólogo de Hamlet suyo comienzo da título a la película), la palabra, decía, da un tono contenido y un sentido profundo a situaciones, por lo demás, bastante grotescas y disparatadas.

En fin, si el discurso verbal que potencia sus cualidades sonoras, melódicas y en definitiva rítmicas no es condición necesaria de la expresión cinematográfica, sí es, desde luego, muy característico, y permite distinguirla netamente de la teatral, basada, como ya afirmaba Hegel, en la totalidad del movimiento, es decir, en los desplazamientos internos y externos de los personajes.

\subsubsection{Ruidos}

En la banda sonora considerada desde el punto de vista de la teoría de la información, la música constituye un ruido respecto del desarrollo narrativo; la música es externa al curso de los acontecimientos, no tiene justificación estructural (salvo contadas ocasiones) y resulta poco verosímil, de ahí el valor convencional y de síntoma de la intención estética que ya comentamos. En este sentido, es el único ruido tolerable. Los demás ruidos han de encajar en la globalidad del filme, $y$, por tanto, han de tener alguna función en el curso de la historia y alguna 
justificación en relación con los acontecimientos narrados. Esto significa que en el transcurso del filme se producen múltiples ruidos ocasionales que sirven para exponer la acción, la situación, el ambiente, la actitud del personaje que los provoca, etc. Ello no impide que actúen rítmicamente, pero lo hacen entrando en correlación con fenómenos de distinta índole, por ejemplo, en Psicosis, en la secuencia del asesinato en la ducha la música se interrumpe y es sustituida por el ruido que hace el agua al salir, hasta que $\mathbf{N}$. Bates cierra el grifo y la música reaparece: un ruido ocasional, justificado narrativamente, pues la mujer es asesinada mientras se está duchando, permite mantener la continuidad sonora y temporal del filme, eludiendo el acompañamiento musical, que resultaría excesivamente enfático y melodramático. En Night on earth, de Jim Jarmusch, los ruidos del tráfico urbano se van poco a poco transformando en la melodía repetitiva de la banda sonora, y viceversa.

Otras veces, la historia permite la irrupción de ruidos persistentes, paralelos a la acción, que constituyen una especie de fondo motivado por el lugar en que aquella se inscribe; ruidos naturales, como los de los ríos, el mar o los pájaros, o ruidos producidos por el hombre y sus instrumentos como los de las locomotoras que suenan a intervalos relativamente regulares en Deseos humanos, de Fritz Lang. Constituyen motivos rítmicos propiamente narrativos, extraídos de las circunstancias de la acción narrada, pero tratados en virtud de su condición sensorial, sometidos a recurrencias más o menos regulares, entre sí y con otros motivos sonoros, de manera que afectan al ánimo del espectador por su propia consistencia sensorial, más allá de su valor directo. Más adelante veremos el modo particular de actuación sobre el espectador.

He analizado por separado estos tres aspectos de la banda sonora para exponer sus características específicas, pero es evidente, y así ha quedado comentado, que frecuentemente forman una trama sonora unitaria organizada métricamente, esto es, sometiendo a distribución y alternancia regular los diversos motivos, con independencia de su valor narrativo. Es curioso, por ejemplo, cómo la edición autónoma de la banda sonora de Paris Texas conserva algunos diálogos que armonizan perfectamente con las partes musicales contiguas.

Esta trama sonora totalizante en la que confluyen ruidos, música y voces evoca fácilmente la definición del poema como «discurso organizado en su trama fónica total», y en efecto, desempeña el mismo papel que la versificación en la poesía. En mi opinión, aunque no utiliza 
como materia inmediata la imagen en movimiento que define al cine, no por ello deja de ser netamente cinematográfica en la medida en que actúa sobre la aprehensión de la sucesión de fotogramas para conferirle un carácter estético, es decir, sensorial y complejo, subjetivo y afectivo, que la percepción únicamente visual alcanza con más dificultad. Sin embargo, hay aspectos métrico-rítmicos más específicamente cinematográficos que ahora vamos a examinar.

\subsection{La narración}

Puede parecer contradictorio incluir a la narración como un factor métrico orientado a la aprensión rítmica del filme, cuando hemos repetido que el ritmo, para conformar un efecto estético, debe trazar su recorrido al margen de la lógica de las acciones contadas, precisamente para «musicalizarlas» y transformar su sentido. Pero nos referíamos antes a una relación de convergencia y disyunción entre dos regímenes de acontecimientos, los estímulos sensoriales del ritmo por un lado, y las acciones y su orientación en la trama, por otro. Las acciones y demás unidades narrativas se ofrecen como unidades métricas precisamente cuando se desprenden de su orientación y se vuelven sobre sí mismas para ser consideradas en su intensidad propia, y no en una cadena de acontecimientos concatenados lógicamente. $Y$ esto se consigue por medio del relato repetitivo.

Como se sabe, en las relaciones temporales de frecuencia Genette distingue el relato iterativo, que narra una sola vez una acción o acontecimiento que se repite con ciertas variaciones de matiz en la historia («todos los años visitábamos al abuelo»), del relato singulativo que cuenta los acontecimientos tantas veces como tienen lugar en la historia; llamamos repetitivo al relato singulativo cuando un mismo acontecimiento ocurre y es contado más de una vez (cuando el relato expone cada visita al abuelo). Por supuesto, la repetición puede tener una función narrativa, renovar la expectación, por ejemplo; pero, es claro que, cuando se desvincula de la sucesión de acontecimientos, el acontecimiento repetido deja de remitir a sus causas y consecuencias (narración), para remitir a otras ocurrencias del acontecimiento que, en distribución regular ac-túan entonces como estímulos rítmicos. Por ejemplo, en Un lugar en el mundo, de Adolfo Aristarain, la carrera desafiante que el niño con su carro tirado por un caballo emprende con la 
locomotora que llega al pueblo se repite cuatro veces, y si bien la primera y la última podrían tener una justificación narrativa, las intermedias constituyen momentos de intensidad rítmica, producidos por la narración (son intrínsecos al relato), pero al mismo tiempo desplazados de ella para constituir una sucesión propia. Lo mismo ocurre con los desplazamientos andando por los caminos que realizan los cómicos de El viaje a ninguna parte.

Particularmente interesante me parece el caso de Los pájaros, el filme de Hitchcock, en el que la recurrencia de la aparición de pájaros agresivos, que se va intensificando gradualmente, empieza siendo rítmica (pues la narración parece referirse a la relación amorosa entre los protagonistas, y los pájaros no son más que un elemento del entorno), para acabar confluyendo con la narración (pues la incertidumbre que permanece se refiere al acoso de estos animales, y se disuelve la primera), sin dejar de ser rítmica, pues la narración no acaba de renovarse ni de resolverse, simplemente los acontecimientos reiterados van acentuándose de manera periódica.

\subsection{El montaje}

El montaje es la organización de los planos de un filme según ciertas condiciones de orden y tiempo. El concepto de «plano» es en cambio ambiguo y problemático pues se aplica al tamaño (primer plano / plano general / plano medio), a la movilidad de la cámara (plano fijo), o a la duración ininterrumpida de un segmento de película. Retenemos esta última acepción, en combinación parcial con la primera. La película es una sucesión de planos (duración) que van sucediéndose y transformándose, por ejemplo, cambiando de tamaño.

Dice Lotman (1979: 83) que «el efecto cinematográfico propiamente dicho se produce a partir del momento en que un plano se compara a otro, es decir, a partir del momento en que en la pantalla surge la narración».

Si bien lo primero, esto es que el efecto cinematográfico procede de la comparación de planos, parece cierto, en cambio, lo segundo, la identificación de efecto cinematográfico, comparación de planos y narración, es, en mi opinión, más discutible, pues la narración surge como un efecto casi convencional del pacto entre texto fílmico y espec- 
tador y, en todo caso, puede surgir ya del primer fotograma, cuando éste suscita interrogaciones acerca del devenir de los acontecimientos.

Desde luego, la sucesión de planos es el vehículo que adopta la narración en el caso del cine y su organización es fundamentalmente narrativa cuando está regida por el único criterio de exponer sin más la sucesión de acontecimientos: pero la aprehensión narrativa compara, relaciona acontecimientos o acciones (esto es, los comportamientos que constituyen las funciones narrativas), pero no planos, es decir segmentos de película con un contenido iconográfico, sí, pero independientes de su significación narrativa, como las sílabas o los acentos, que articulan el ritmo con independencia de la significación de la palabra que los manifiesta.

Se notará, entonces, que el efecto cinematográfico, si hemos de conservar la definición de Lotman es, más que la narración, el ritmo, pues en el caso de que los planos sean susceptibles de comparación por sí mismos y no por su sentido, tal comparación habrá de referirse a las formas de la imagen y sus variaciones (tamaño y duración del plano, relación con la cámara, etc.), esto es, a los aspectos visuales y sus semejanzas-recurrencias, y no a los semánticos.

Cuando la comparación de planos, para conservar la expresión de Lotman, aunque parece claro que se trata de una operación inconsciente o intuitiva, en la que el espectador se deja guiar por los estímulos sensoriales de la imagen, lleva al espectador a descubrir repeticiones y equivalencias entre ellos, éste se ve impulsado a anticipar la regularidades futuras, y ese movimiento anticipatorio es la forma que el ritmo adquiere cuando se inscribe en el organismo del espectador.

Pero no hay que confundir este movimiento que realiza el cuerpo mismo del sujeto, movimiento fundamentalmente sensorial, con la incertidumbre sobre el futuro de los acontecimientos, por lo tanto con la anticipación de su resolución, que es más bien intelectual y, desde luego, narrativa. En el primer caso hay ritmo, como en Ciudadano Kane; en el segundo, suspense, como en El tercer hombre.

Cuando las cimas de intensidad del ritmo coinciden con el planteamiento, el recuerdo o la resolución de las incertidumbres narrativas, el ritmo y el suspense se superponen, y el primero no es sino una forma de énfasis. Cuando, por el contrario, hay tensión y alternan las confluencias con las bifurcaciones, la asimilación rítmica de la sucesión se impone, formando la respuesta estética. Entiendo que esta tensión y desfase entre la organización del plano y la sintaxis narrativa es el 
equivalente visual de la música y la métrica en la poesía, y produce efectos semejantes, es decir renueva el sentido y lo vuelve sensible, experimentado sensorialmente.

Hay una definición de ritmo cinematográfico (Chartrier, Martin, 1962: 159) muy citada que puede servir de base para explicar su funcionamiento:

«Un plano no se percibe del principio al fin de la misma manera. Al principio se le examina y sitúa; aparece, si se quiere, expuesto. Entonces, se presta una atención máxima, para captar el significado, la razón de ser del plano, al gesto, palabra o movimiento que hacen progresar la acción. Después, la atención se atenúa y si el plano se prolonga surge el aburrimiento y la impaciencia. Si cada plano termina exactamente cuando baja la atención, siendo reemplazado por otro, la atención se mantendrá sin cesar interesada, poseyendo el film un ritmo. El ritmo cinematográfico no es, pues, la aprehensión de las relaciones temporales existentes entre los planos, sino la coincidencia entre la duración de cada plano y los movimientos de atención que suscita y satisface. No se trata de un ritmo temporal abstracto, sino de un ritmo de atención».

Como subraya el propio Marcel Martin, hay poco que añadir a esta excelente definición de ritmo. Efectivamente, el ritmo es cuestión de aprehensión, por lo tanto subjetiva, que hay que localizar en el organismo del espectador (en sus movimientos de atención) antes que en el objeto que la suscita; sin embargo, el objeto prevé los movimientos del espectador en su estructura, en su particular modo de organización, los momentos de atención han de tener su correspondencia formal en circunstancias del filme, en aspectos del plano mismo procedentes de su propia naturaleza visual y temporal.

La combinación de los dos elementos constitutivos del plano, la duración y el tamaño, es aquí fundamental: la duración como marco en el que se manifiesta el movimiento, el tamaño como expresión de la intensidad, pues el ritmo no es sino la realización de relaciones de intensidad en las relaciones de duración (Mitry, 1966: 419): la expectativa de una intensidad que cuando se satisface se renueva. Podemos vincular la intensidad y el ritmo con lo que Deleuze (1984: 131 y ss.) llama imagenafección, que identifica precisamente con el primer plano (tamaño e intensidad); en la imagen-afección el movimiento deja de ser de traslación (que implica duración) para convertirse en movimiento de expresión, que implica intensidad, pero también potencialidad, tensión y tendencia, así pues expresión y anticipación, pero a causa de su intensidad intrínseca y no del estado de cosas que representa (Deleuze, 1984: 145). 
El primer plano, o sus equivalentes formales, como algunas tomas angulados o encuadres paradójicos, juegan, entonces, el papel de jalones métricos, cimas de intensidad que regulan la atención y el movimiento interno del espectador con medios visuales. A ellos habría que añadir, en un nivel de concreción más elevado, cercano a la representación y, por tanto a la narración, la recurrencia de colores, el tratamiento de la imagen con filtros que deforman la tonalidad de la fotografía, y, sobre todo, la regulación de las luces y las sombras, los blancos, los negros y los grises cuya alternancia regular y gradual constituye un estímulo fuerte que mueve el organismo del espectador y constituye el sustento rítmico de algunos filmes emblemáticos como Dies irae, de Dreyer.

En suma, el montaje, considerado en sentido amplio, abarca y actúa sobre todos los estímulos cuya organización métrica da lugar a la experiencia rítmica del filme. El método de trabajo de una montadora, Agnès Gillemont, que suele utilizar un esquema de conjunto de la película, escrito unas veces sobre papel pautado y otras sobre papel de contabilidad, al que llama significativamente "partitura»o «trenecito», revela la necesidad de tener en cuenta el peso y la duración de los distintos elementos que intervienen en el filme, sus correlaciones, repeticiones y amalgamas, en fin, sus cualidades sensoriales consideradas en su cantidad y en su posición con respecto a las de su misma naturaleza. «Se trata de hojas similares a las de la mezcla de sonido, pero preparadas desde el principio del montaje, que evolucionan con él; es el montaje de la película pasado a papel, lo que permite sentir su ritmo, sus repeticiones» ${ }^{1}$, o mejor, puesto que el ritmo sólo se siente en la percepción del filme, observar panorámicamente, en su totalidad, los estímulos que habrán de desencadenarlo.

\section{CONCLUSIÓN}

Al comienzo de este trabajo reuníamos dos definiciones de ritmo, una ligada al objeto que lo promueve, definición básicamente métrica:

1 Seguimos el testimonio de Dominique Villain (1994: 49-51). Agnès Guillemont ha montado diez películas de Jean-Luc Godard, cuatro películas de François Truffaut, etc. Sus partituras son útiles para cuestiones de construcción, para revelar la duración inadecuada de algún plano, la necesidad de un sonido determinado en un momento determinado, la desaparición excesiva de algún elemento, etc., todas ellas cuestiones que afectan a la aprehensión sensorial del conjunto, es decir, al ritmo. 
alternancia regular en el tiempo de fenómenos comparables; y otra definición que, remitiéndose todavía al objeto, implica sobre todo su realización en el sujeto, la forma del movimiento. Quisiera ahora para terminar intentar conjugar estos dos aspectos a propósito del ritmo cinematográfico.

Como se vio, en el desarrollo del filme intervienen tres órdenes de estímulos rítmicos, tres clases de fenómenos sometidos a alternancia regular: los auditivos de la banda sonora, los visuales de la imagen y los narrativos de las acciones y los acontecimientos, que, por otra parte, se manifiestan también de manera sonora y visual. La regularidad no es el ritmo, sino la circunstancia que lo provoca porque lleva a anticipar los estímulos futuros y así crear ese movimiento interior organizado que es el ritmo propiamente dicho. Por ello no es de extrañar que las regularidades del cine no sean rígidas, ni sistemáticas, ni numerosas, ni del mismo orden (como ocurre en el verso libre, que va transformando sus propias regularidades, en vez de repetirlas de la manera sistemática y absolutamente previsible propia de la métrica tradicional): para provocar el efecto rítmico basta con que el plano invoque un estímulo futuro de los planos siguientes, y esto puede hacerlo por medio de cualquiera de los tipos de fenómenos que hemos considerado y analizado por separado. Sin embargo, en el caso de la percepción cinematográfica tales fenómenos actúan conjuntamente, planteando sutiles homologías funcionales entre la imagen, el sonido y el suceso, que, no lo olvidemos, constituyen los estímulos métricos, pero no son todavía ritmo, el ritmo es la experiencia motora que tenemos del objeto en la cual vivimos su sentido, y esa experiencia es una respuesta unitaria a los estímulos sinestésicos. Que no haya un movimiento de traslación efectivo, como en el baile, no significa que no haya experiencia del movimiento. El ritmo, la forma del movimiento, incluye, en virtud de su carácter anticipatorio, la llamada cinefantasía, gracias a la cual podemos vivir un movimiento (no pensarlo) sin necesidad de ejecutarlo, como cuando nos disponemos a realizar una acción que se ve abortada por cualquier causa, pues «una fase muy pequeña del movimiento (por ejemplo, una ligera contracción muscular) puede bastar para representar al movimiento entero" (Sartre, 1940: 107; vid. también Gehlen, 1980: 225-227).

El ritmo del filme, subraya Michel Chion (1993:130), no es un fenómeno ni específicamente sonoro ni específicamente visual, pues la vista y el oído no son sino los canales por los que aprehendemos los fenómenos: «Después de haber entrado en el oído o el ojo, el fenómeno nos afecta en algún área cerebral conectada con las áreas de la 
motricidad y sólo en este nivel es rítmicamente descodificado», siendo, naturalmente esta descodificación motora el ritmo mismo.

En fin, si Octavio Paz (1976: 278), ha resuelto esta condición sinestésica de la poesía diciendo que en la lectura del poema «oímos mentalmente lo que vemos», en el caso del cine podríamos decir que respiramos (rítmicamente, en un acto unitario) con el oído, la vista y la imaginación.

\section{Referencias bibliográficas}

AdoRno, TH. W. y EISLER, H. (1981). El cine y la música. Madrid: Fundamentos.

Aumont, J. y MARie, M. (1990). Análisis del film. Barcelona: Paidós.

BENVENISTE, E. (1973). «La notion de «rythme» dans son expression linguistique». En Problèmes de linguistique générale, 327-335. París: Gallimard.

CHION, M. (1993). La audiovisión. Barcelona: Paidós.

DELEUZE, G. (1984). La imagen-movimiento. Estudios sobre cine 1. Barcelona: Paidós.

Domin, H. (1986). ¿Para qué la lírica hoy?. Barcelona: Alfa.

GEHLEN, A. (1980). El hombre. Salamanca: Sígueme.

LANGER, S. K. (1967). Sentimiento y forma. México: Universidad Nacional Autónoma de México.

LENNEBERG, E.H. (1967). Fundamentos biológicos del lenguaje. Madrid: Alianza, 1975.

LOTMAN, Y. (1979). Estética y semiótica del cine. Barcelona: Gustavo Gili.

MARTIN, M. (1962). La estética de la expresión cinematográfica. Madrid: Rialp.

Mitry, J. (1966). Estética y psicología del cine. I. Las estructuras. México: Siglo XXI.

PAZ, O. (1976). El arco y la lira. México: F.C.E.

SARTRE, J.-P (1940). L'imaginaire. Paris.

VILlAIN, D. (1994). El montaje. Madrid: Cátedra. 